\title{
Ekspo Potensi Budaya Desa Bersaudara sebagai Upaya Peningkatan Modal Sosial dalam Program Sister Village
}

\author{
Kanthi Pamungkas Sari ${ }^{1 *}$, Priyo ${ }^{2}$, Ahwy Oktradiksa ${ }^{1}$, Agus Setiawan ${ }^{3}$
}

${ }^{1}$ Prodi PGMI, Universitas Muhammadiyah Magelang, Jl. Mayjend Bambang Soegeng km 5 Mertoyudan, Magelang, Indonesia, 56172

2Prodi Profesi Ners, Universitas Muhammadiyah Magelang, Jl. Mayjend Bambang Soegeng km 5 Mertoyudan, Magelang, Indonesia, 56172

${ }^{3}$ Prodi Teknik Informatika, Universitas Muhammadiyah Magelang, Jl. Mayjend Bambang Soegeng km 5 Mertoyudan, Magelang, Indonesia, 56172

*Email koresponden: kpamungkassari@ummgl.ac.id

\author{
ARTICLE INFO \\ Article history \\ Received: 03 July 2020 \\ Accepted: 21 Okt 2020 \\ Published: 23 Apr 2021
}

\section{Kata kunci:}

Modal sosial

Potensi budaya

Sister village

\begin{abstract}
A B S T R A K
Background: “Ekspo Potensi Budaya Desa Bersaudara” merupakan salah satu kegiatan empowering yang dapat meningkatkan peran modal sosial sebagaimana yang diharapkan. Metode: Pada kegiatan ini mereka melibatkan perwakilan dari seluruh elemen masyarakat yang ada sehingga dapat berinteraksi dan bekerjasama secara langsung. Selama ini mitigasi bencana alam lebih banyak diarahkan pada pengembangan modal manusia jika dibandingkan dengan modal sosial. Padahal modal sosial memberikan manfaat positif dalam mitigasi bencana. Metode yang digunakan dalam kegiatan adalah metode Participatory Rural Apraisal (PRA) dan demonstrasi. Hasil: Kegiatan pengabdian pada masyarakat yang didapatkan yaitu setiap elemen masyarakat yang terlibat mampu menjalin interaksi yang lebih erat dengan tetap menyadari bahwa mereka sebagai bagian dari Desa Bersaudara dan memiliki kesepakatan untuk melakukan kegiatan-kegiatan bersama sesuai dengan potensi masing-masing. Kesimpulan: Serangkaian kegiatan ini diharapkan dapat meningkatkan peran modal sosial dalam mitigasi bencana erupsi Gunung Merapi yang dapat terjadi sewaktu-waktu
\end{abstract}

\begin{abstract}
Keyword:
Cultural potential

Sister village

Social capital

A B S T R A C T

Background: "The Culture of Sister Village Potential Expo" is one of the empowering activities that can increase the role of social capital as expected. Method: In this activity, they involve representatives from all elements of society so that they can interact and collaborate directly. So far, natural disaster mitigation has been more focused on developing human capital than social capital. Social capital provides positive benefits to disaster mitigation. The method used in the activity is the Participatory Rural Appraisal (PRA) method and demonstrations. Result: The result of community service is that every element of society is involved and builds closer interaction and realizes that they are part of the sister Village and have an agreement to carry out activities together according to their respective potential. Conclusion: All of the activities expected to increase the role of social capital in mitigating the eruption of Mount Merapi that can erupt at any time.
\end{abstract}

\section{PENDAHULUAN}

Kabupaten Magelang Propinsi Jawa Tengah adalah daerah potensi rawan bencana alam khususnya erupsi gunung berapi dan gerakan tanah. Potensi tersebut terjadi sebagai akibat dari 
kondisi hidrologi, geologi, dan morfologi wilayah dan adanya Gunung Merapi. Kabupaten Magelang memiliki posisi wilayah yang dikelilingi beberapa gunung dan satu diantaranya yang masih aktif adalah Gunung Merapi. Sebenarnya erupsi telah ditetapkan rata-rata empat tahunan, namun setelah erupsi tahun 2010 rupanya kondisi tersebut telah mengalami perubahan. Dan sampai saat ini belum ditetapkan kembali (Permana, 2020).

Berdasarkan hasil pengkajian kerusakan dan kerugian, erupsi Gunung Merapi yang terjadi pada tahun 2010 mengakibatkan kerugian yang di tanggung oleh masyarakat Kabupaten Magelang sangat besar. Dari dokumen yang diperoleh dari Badan Penanggulangan Bencana Daerah (BPBD) Kabupaten Magelang tercatat mencapai Rp. 661.173.000.000,00 terdiri dari kerusakan senilai Rp. 316.767.000.000,00 dan kerugian senilai Rp. 344.416.000.000,00. Selain itu juga terdapat 52 orang meninggal dunia dan 98 mengalami luka atau sakit. Pada saat terjadinya erupsi terdapat lebih dari 22.500 orang yang mengungsi di 152 titik baik itu di wilayah Kabupaten Magelang, wilayah Kota Magelang dan wilayah Kabupaten Temanggung. Fakta yang terjadi, begitu Gunung Merapi Erupsi para pengungsi menyebar, panic menuju ke wilayah-wilayah yang dinilai aman. Namun proses mengungsi masyarakat di kawasan rawan bencana (KRB) tanpa adanya koordinasi atau petunjuk dari pihak-pihak terkait yang berarrti. Banyak yang mengungsi ke desa lain namun seketika itu ditolak karena desa tersebut sudah menerima pengungsi dari desa lainnya atau tidak siap menerima pengungsi yang jumlahnya banyak bahkan mengungsi bersama binatang ternaknya dan akibatnya pengungsi harus mencari lagi ketempat lain meski dengan terpaksa harus terpisah dengan keluarganya (BNPB, 2011) .

Berdasarkan Peraturan Bupati Magelang Nomor: 17 tahun 2011 tentang Fungsi BPBD Kabupaten Magelang, Pemda telah menetapkan upaya-upaya mitigasi bencana secara berencana bertahap dan berkesinambungan bersama pihak-pihak pemangku kepentingan. Meski tujuan dari mitigasi bencana adalah meminimalisir korban maupun kerugian dari akibat bencana namun banyak kendala yang muncul diantaranya adalah:

a. Kinerja Aparat dan lembaga-lembaga penanggulangan bencana di daerah belum memadai. Problematika yang muncul diantaranya yaitu: 1) Akurasi basis data yang tidak termutakhirkan; 2) Assesemen kerugian dan kerusakan pasca bencana yang kurang akurat; 3) Terhambatnya analisis kerusakan spasial akibat dari keterbatasan peta wilayah yang dimiliki; 4) Alokasi pendanaan rekonstruksi dan rehabilitasi dari pemerintah daerah yang terbatas.

b. Rendahnya pengetahuan dan pemahaman masyarakat terhadap resiko bencana serta kesiapsiagaan menghadapi bencana. Masalah yang muncul antara lain: 1) Jaringan informasi dan komunikasi yang terbatas dalam penyebaran ke masyarakat informasi kebencanaan kepada masyarakat; 2) Pengurangan risiko bencana belum terintegrasi dalam perencanaan pembangunan secara komperhensif; 3) Belum memiliki panduan dan atau SOP yang jelas terkait mitigasi bencana (Renstra, 2014).

Salah satu upaya untuk mengatasi kendala-kendala yang muncul di atas yaitu menyelenggarakan program Desa Bersaudara (sister village) yang dicetuskan sejak tahun 2011 pasca erupsi Gunung Merapi. Tercatat sampai sekarang ada 19 sister village yang telah ditetapkan di Kabupaten Magelang dengan melibatkan 47 Desa. 19 Desa KRB III yang berada di Kecamatan 
Sawangan, Dukun, Srumbung dan 28 Desa Penyangga yang berada di Kecamatan Sawangan, Pakis, Muntilan, Mungkid, Ngluwar, Salam, Srumbung, Mertoyudan (RKPD Kabupaten Magelang, 2016). Masing-masing pasangan telah membuat kesepakatan dengan difasilitasi BPBD Kabupaten, selanjutnya kesepakatan-kesepakatan tersebut diharapkan dapat ditindaklanjuti secara berkesinambungan sehingga diantara persaudaraan yang terjadi akan menjadi lebih erat, lebih terjalin rasa kekeluargaannya. Jika terjadi bencana erupsi Gunung Merapi sewaktu-waktu dan harus terjadi pengungsian maka rasa nyaman, rasa aman akan dirasakan oleh kedua belah pihak dan social disorder dapat lebih diminimalisir.

Sejak tahun 2014 antara Desa Krinjing dengan Desa Deyangan telah menerbitkan Surat Kesepakatan Bersama Nomor: 140/001/XI/2014 tertanggal 10 Nopember 2014 tentang Pelaksanaan Program Sister Village (Sari et al., 2018). Kegiatan-kegiatan yang telah dilakukan sebagai konsekuensi logis dari kesepakatan tersebut masih diorientasikan ke pengembangan modal manusia, parsial dan bersifat eksklusif. Belum pada pengembangan modal sosial yang mereka miliki secara inklusif. Di antara kegiatan yang telah dilakukan misalnya kegiatan peningkatan pengetahuan dan keterampilan mitigasi bencana yang difasilitasi BPBD atau pihak lain hanya diikuti oleh beberapa perangkat desa; kunjungan silaturahmi terjadi jika ada undangan hajatan dari salah satu perangkat desa. Sampai saat ini belum pernah melakukan kegiatan bersama yang melibatkan perwakilan elemen masyarkat yang ada, sehingga kapasitas masing-masing desa dalam program sister village mengalami peningkatan yang berarti.

Desa Krinjing dengan Desa Deyangan didampingi oleh Tim Program Pengembangan Desa Mitra (PPDM) dari Universitas Muhammadiyah Magelang melakukan empowering dengan secara bertahap dan berkesinambungan agar dapat meningkatkan peran modal sosial sebagaimana yang diharapkan. Berdasarkan hasil musyawarah, perlu melakukan kegiatan-kegiatan yang dapat meningkatkan peran modal sosial dengan melibatkan perwakilan elemen-elemen masyarakat. Kegiatan tersebut adalah Ekspo Potensi Budaya Desa Bersaudara, yang memiliki tujuan agar dapat saling mengenal, berinteraksi dan bekerjasama secara langsung, sebagaimana potensi yang dimiliki masing-masing desa.

\section{MASALAH}

1. Dalam rangka mitigasi becana perlu lebih banyak diarahkan ke pengembangan modal sosial sehingga akan berdampak positif pada kegiatan-kegiatan mitigasi bencana erupsi Gunung Merapi

2. Sejak diterbitkannya Surat Kesepakatan Bersama antara Desa Krinjing Kecamatan Dukun sebagai desa KRB III dengan Desa Deyangan Kecamatan Mertoyudan dalam melaksanakan program sister village, belum pernah memiliki kegiatan bersama yang dilembagakan.

\section{METODE PELAKSANAAN}

1. Participatory rural appraisal (Coghlan \& Brydon-Miller, 2014). Ekspo Potensi Budaya Desa Bersaudara ini bukan merupakan kegiatan tunggal. Kegiatan ini merupakan bagian dari rangkaian empowering yang dapat meningkatkan kapasitas sebagai Desa Bersaudara dengan memperkuat potensi masyarakat. Penguatan meliputi langkah-langkah nyata mengenali 
kembali peran sebagai desa yang berasal dari KRB III (yang nantinya akan mengungsi dan peran sebagai Desa Penyangga pengungsi jika terjadi erupsi Gunung Merapi sewaktu-waktu terjadi. Berikut ini langkah-langkah yang dilakukan dalam kegiatan PRA:

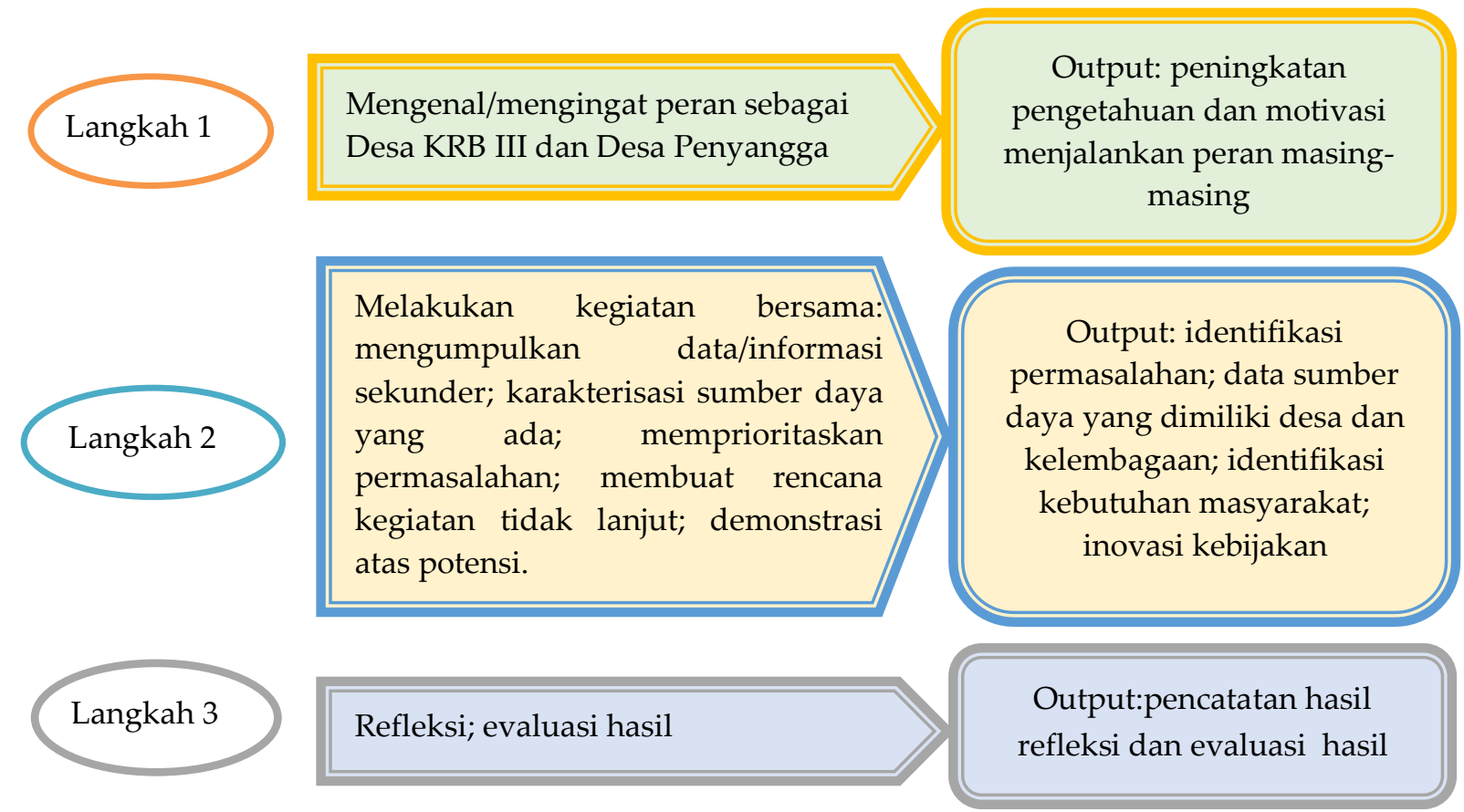

Gambar 1. Langkah-langkah pelaksanakan kegiatan

2. Demonstrasi, dengan menyelenggarakan ekspo lima kelompok kesenian dari kedua desa. Desa Deyangan menampilkan kelompok kesenian: Pitutur, Rampak Macan dan Topeng Ireng. Sedangkan Desa Krinjing menampilkan kelompok kesenian Cakalele dan Jathilan Gedruk. Masing-masing diberikan kesempatan untuk tampil di halaman Tempat Evakuasi Akhir (TEA) Desa Deyangan selama sehari penuh.

3. Seluruh rangkaian kegiatan PRA dan Demonstrasi diselenggarakan pada bulan Nopember 2019

\section{HASIL DAN PEMBAHASAN}

\section{Manfaat Modal Sosial dalam Program Sister Village}

Paradigma penanganan bencana yang telah bergeser dengan memberikan ruang yang lebih besar kepada masyarakat. Pemerintah telah merancang sebuah pendekatan pengurangan resiko bencana alam berbasis masyarakat. Harapannya dapat memotivasi masyarakat agar lebih banyak berpartisipasi atau berkontribusi aktif mulai kesiapan, kesiapsiagaan dalam keadaan darurat, dan recovery, perencanaan, pelaksanaan sampai pada monitoring evaluasi (Kusumasari, 2014).

Manajemen mitigasi bencana yang dilakukan sebelum tahun 2011 belum banyak melibatkan masyarakat sebagai subyek. Akibatnya, kerugian yang harus ditanggung akibat bencana erupsi Gunung Merapi sangat besar (Sari et al., 2018). Distribusi bantuan dari berbagai pihak juga tidak merata di tempat pengungsian. Hal ini terjadi karena paradigma dalam mitigasi bencana masih kearah tanggap darurat. Pola pengungsian belum terancang dan terkoordinir dengan baik, seolah- 
olah berjalan dengan natural. Hal tersebut dibuktikan dengan masih ada beberapa kelompok masyarakat yang menolak datangnya pengungsi. Sedangkan sampai saat ini pemerintah daerah Kabupaten Magelang baru memiliki 17 Tempat Evakuasi Akhir (TEA) yang masing-masing memiliki kapasitas daya tampung 500 orang. Sehingga baru dapat menampung 8.500 orang. Jadi masih diperlukan tempat-tempat pengungsian yang harus dikelola oleh masyarakat secara mandiri.

Setiap upaya mitigasi bencana alam tidak akan terwujud apabila masyarakat tidak mempunyai pengetahuan dan keterampilan dalam mengelola bencana secara maksimal. Hal ini disebabkan karena masyarakat dengan segala kapasitas yang dimiliki seharusnya dijadikan sebagai subyek yang menjalankan peran dalam mitigasi bencana (Takeuchi.Y et al., 2011) Sebagai subyek masyarakat akan menggunakan semua potensi dan kemampuan yang dipunyai dalam merespons bencana, mengurangi resiko bencana.

Salah satu unsur penting dalam mitigasi bencana adalah modal sosial, tak terkecuali dalam implementasi program sister village. Menurut Korten (1986); Aswasulasikin (2017) modal sosial adalah kapasitas potensi masyarakat secara internal sebagai wujud energi sosial yang perlu dimanfaatkan secara maksimal. Terbentuk karena adanya proses interaksi sosial yang terus menerus. Relasi ini akan berdampak pada hubungan antara individu-individu yang membangun, norma, kepercayaan dan jaringan sosial (Putnam, 2000; Bhandari, 2014). Oleh karena itu modal sosial merupakan potensi yang harus dipahami, dieksplorasi, dikuatkan dan dijaga agar bermanfaat dalam kehidupan. Modal sosial memiliki manfaat yang mencakup: (a) bonding, yaitu ikatan antar individu dalam situasi rutin yang sama dan dekat, (b) bridging, yaitu ikatan dari beberapa orang yang lebih luas dan (c) linking, yaitu ikatan orang-orang di luar komunitas yang dapat mendorong individu untuk dapat memanfaatkan sumber daya yang sebanyak-banyaknya (Field, 2005; Tohani \& Wibawa, 2019).

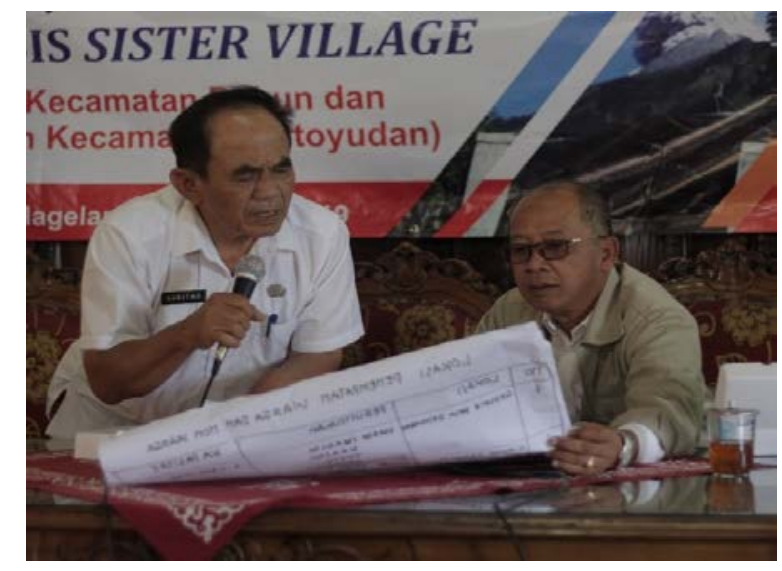

Gambar 2. Kades Krinjing dan Kades Deyangan dalam Forum PRA

Sejak tahun 2018 Desa Deyangan sebagai Desa Penyangga dalam implementasi program sister village Bersama tim PPDM Universitas Muhammadiyah Magelang melakukan upaya-upaya revitalisasi program sister village. Kegiatan yang dilakukan secara bertahap dan berkesinambungan mulai dari: a) Enabling: membangun suasana yang memungkinkan potensi masyarakat Deyangan berkembang ke arah tujuan sebagai Desa Penyangga. Upaya-upaya 
dilakukan adalah dengan mendorong (encourage), memotivasi dan membangkitkan kesadaran (awareness) akan potensinya serta berupaya mengembangkannya, b) Empowering: meningkatkan kapasitas dengan memperkuat potensi masyarakat. Perkuatan ini meliputi langkah-langkah nyata seperti penyediaan berbagai masukan (input) serta pembukaan akses kepada berbagai peluang yang dapat membuat masyarakat menjadi makin berdaya, dan c) Protecting: melindungi potensi dengan mengembangkan sistem perlindungan bagi masyarakat agar tetap berdaya. Dalam proses pemberdayaan diarahkan pada kemandirian atas pengelolaan potensinya

Sebelum Ekspo Potensi Budaya Desa Bersaudara diselenggarakan, Desa Krinjing dan Desa Deyangan bersama Tim PPDM melaksanakan PRA terlebih dahulu terkait dengan manfaat modal sosial dan juga kondisi-kondisi yang diharapkan. PRA dihadiri oleh 36 orang yang terdiri dari Perwakilan BPD, Kepala Desa, Ketua Lembaga Penanggulangan Bencana Desa (LPBDes) dan Perangkat Desa. Berikut hasil dari PRA tersebut:

Tabel 1. Tabel Manfaat Modal Sosial dan Kondisi yang Diharapkan

\begin{tabular}{|c|c|}
\hline Manfaat Modal Sosial & Kondisi yang Diharapkan \\
\hline Bonding & $\begin{array}{l}\text { - Anggota masyarakat memiliki rasa saling perduli dalam } \\
\text { banyak hal } \\
\text { - Rasa kekeluargaan yang lebih kuat antara Desa Krinjing } \\
\text { dan Desa Deyangan } \\
\text { - Keikhlasan untuk memberikan bantuan moril maupun } \\
\text { materiil sesuai dengan kapasitas dan kemampuannya }\end{array}$ \\
\hline Bridging & 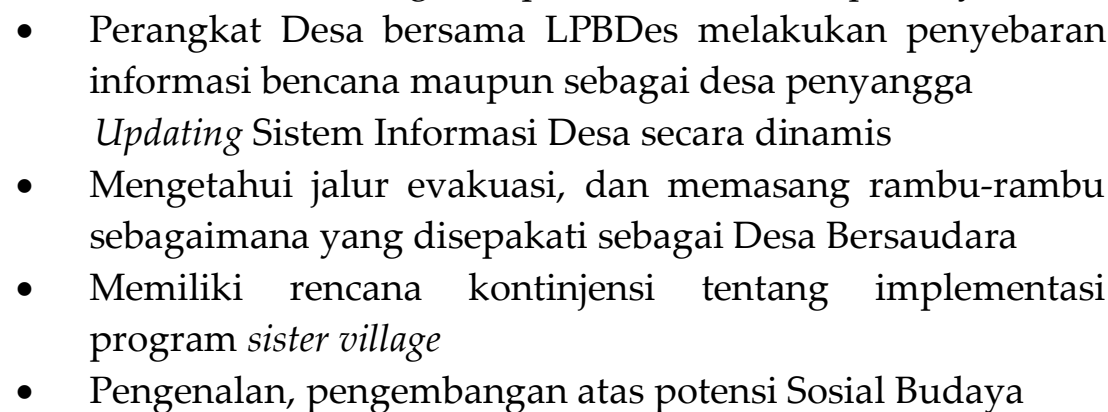 \\
\hline Linking & $\begin{array}{l}\text { - Memiliki mekanisme penanganan bencana tersentral } \\
\text { - Penyebaran informasi penanganan bencana dengan pihak } \\
\text { - Peningkatan pengetahuan early warning system } \\
\text { - Peningkatan pengetahuan manajemen barak, air bersih, } \\
\text { MCK yang layak bagi kemanusiaan serta keterampilan } \\
\text { - } \quad \text { Simulang kegawatdaruratan }\end{array}$ \\
\hline
\end{tabular}

\section{Ekspo Potensi Budaya Desa Bersaudara}

Guna mengoptimalisasikan manfaat modal sosial diantara kedua Desa Bersaudara utamanya pada manfaat bridging atau mengikat komunitas secara luas, sepakat untuk menyelenggarakan Ekspo Potensi Budaya Desa Bersaudara pada bulan November 2019 di halaman TEA Desa Deyangan. Kegiatan dilakukan di panggung terbuka dengan mendatangkan anggota masyarakat masing-masing. Hal ini bertujuan untuk meningkatkan interaksi dan Kerjasama secara langsung. 
Ada 5 jenis kesenian sebagai potensi budaya utama yang dimiliki dan di tampilkan secara bergantian pada saat ekpo berlangsung. Desa Deyangan menampilkan tiga grup kesenian, dan Desa Krinjing menampilkan dua grup kesenian.

\section{Kesenian Pitutur}

Kesenian Pitutur merupakan salah satu kesenian yang dipentaskan oleh masyarakat Desa Deyangan. Isi kesenian Pitutur adalah "macapat dan shalawatan". Kesenian Pitutur ini mengandung banyak ajaran budi pekerti luhur dan nasihat-nasihat baik yang disampaikan (Widodo \& Sujito, 2017). Mulai dari ajakan untuk memiliki budi pekerti yang baik, menjaga lingkungan, sampai pada perilaku tolong menolong dalam kebaikan, keselamatan bersama sampai kewaspadaan dalam setiap tanda-tanda alam. Dalam melantunkan macapat dan shalawat, kesenian Pitutur diiringi oleh rebana yang dimainkan oleh 7 orang anggota.

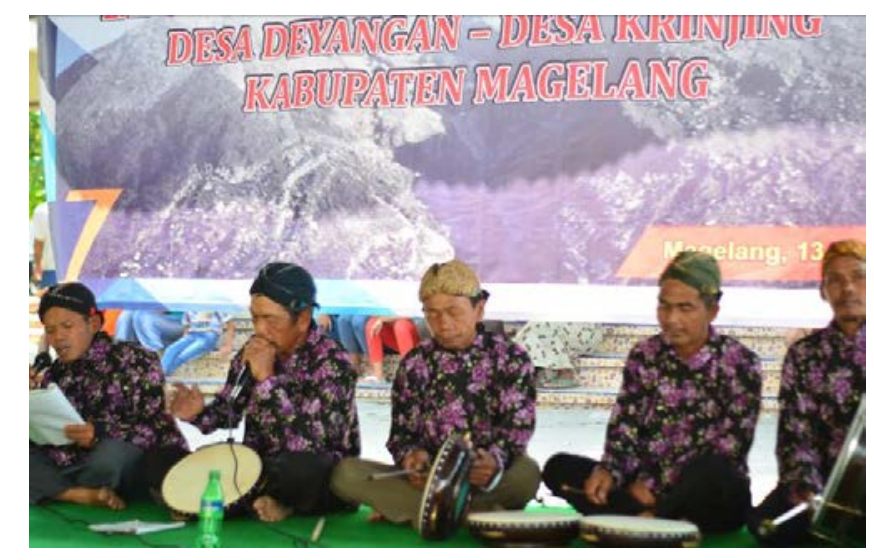

Gambar 3. Kesenian Pitutur

\section{Jathilan Rampak Gedruk}

Jathilan Rampak Gedruk, atau yang sering disebut sebagai Tari Rampak Buto, merupakan satu diantara kesenian yang dipertunjukan oleh kelompok para seniman dari Desa Krinjing dalam ekspo ini. Kesenian yang berasal dari Magelang ini kemudian dikembangkan di sekitar kota kabupaten di sekitarnya. Musik yang mengiringi seperti jathilan, bedanya gerakan hentakan kaki dan kelincahannya menjadi ciri khas kesenian ini. Gerakan hentakan kaki menggambarkan kemarahan yang besar dari raksasa atau " buto" yang membuatnya agar nampak sehebat manusia (Mawadda, 2019) . Tim kesenian Jathilan Rampak Gedruk ini dimainkan secara harmoni dan kompak oleh 20 orang pemain. 


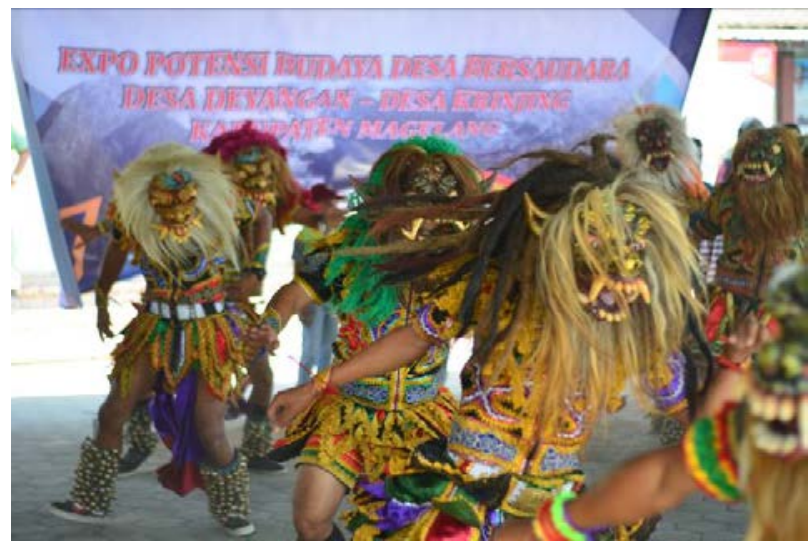

Gambar 4. Jathilan Rampak Gedruk

\section{Topeng Ireng}

Topeng Ireng merupakan tari yang dilaksanakan menyerupai pencak silat yang berpadu dengan syiar agama Islam. Kesenian yang dipentaskan oleh masyarakat Desa Deyangan. Konon ceritanya tarian tersebut semula memang memiliki Gerakan-gerakan silat silat. Kemudian masyarakat menyamarkannya menjadi tarian yang diiringi oleh rebana yang di variasi dengan gamelan tradisional karena pada waktu itu melakukan latihan silat tidak diperbolehkan pada waktu kolonial Belanda berkuasa. Konon menurut informasi yang ada kesenian Topeng Ireng merupakan singkatan dari "toto lempeng dengan iringan irama yang kenceng", maknanya menyusun tatanan yang lurus dengan irama yang keras. Sehingga kalau kita lihat para pemain kesenian ini penarinya akan selalu berada pada barisan yang lurus dan diiringi oleh gamelan tradisional yang berirama penuh semangat (Hapsari, 2013) . Kesenian ini seolah-oleh menggambarkan kerasnya kehidupan masyarakat yang ada di lereng Gunung Merapi namun mereka harus mampu berupaya untuk menata kondisi agar tetap berada pada barisan yang lurus sekaligus bersahabat dengan alam.

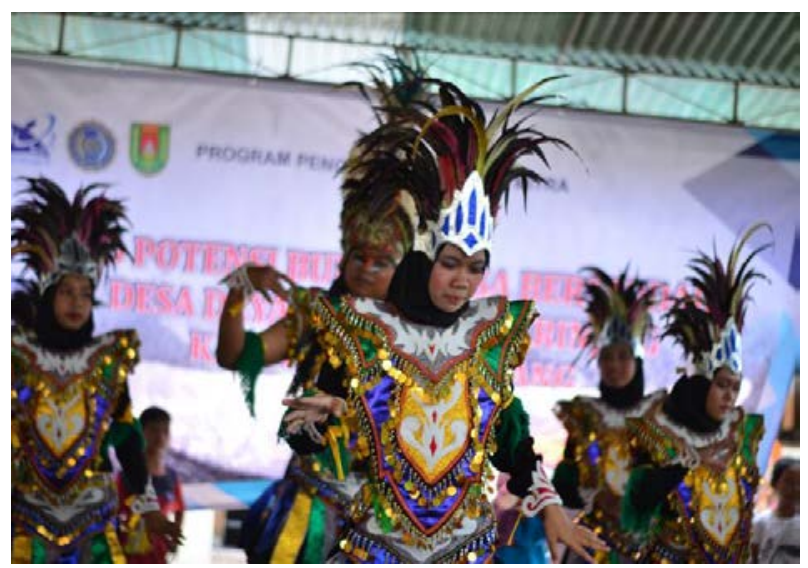

Gambar 5. Topeng Ireng

\section{Tari Cakalele}

Tari Cakalele dipentaskan oleh kelompok kesenian dari Desa Krinjing. Tari ini memang bukan tarian asli dari Jawa Tengah, namun mereka mempunyai kelompok kesenian yang sering mementaskannnya. Tari ini menggambarkan tarian perang, paling sering ditampilkan pada acara 
perayaan adat. Kesenian tersebut dimaknai sebagai perwujudan dari cara menghargai dan menghormati terhadap nenek moyang mereka. Disamping itu juga menggambarkan bahwa masyarakat di lereng Gunung Merapi memiliki jiwa yang pemberani, memiliki jiwa yang tangguh sehingga mereka akan menghadapi situasi kehidupan ini dengan baik (Pangalila et al., 2014). Tari Cakalele di pentaskan oleh lebih dari 20 orang. Meski diselingi dengan aksi gerakan yang mengundang gelak tawa, mereka secara kompak menari secara harmoni dan apik dengan peran mereka masing-masing.

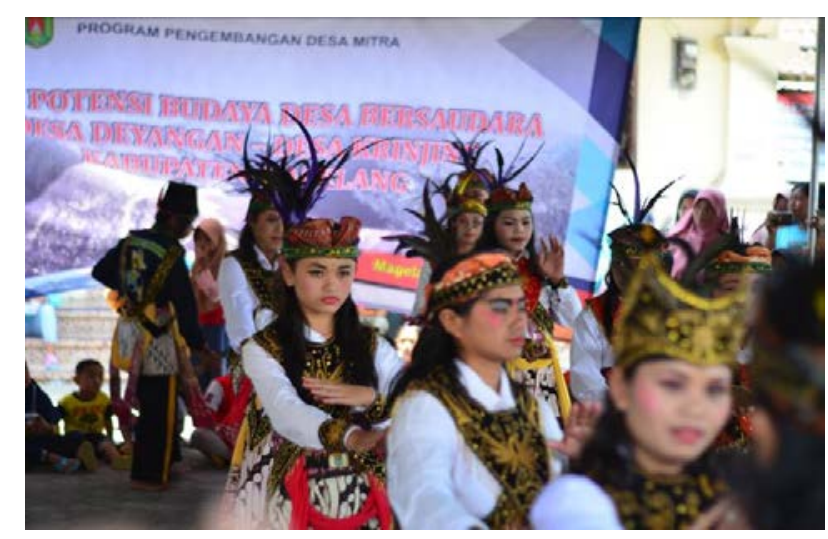

Gambar 6. Tari Cakalele

\section{Rampak Macan}

Rampak Macan dipentaskan oleh kelompok kesenian Desa Deyangan. Kesenian ini menampilkan 4 ekor macan yang diperankan oleh para penarinya. Masing-masing memiliki warna yang berbeda-beda yaitu putih, orange dan kuning. Perbedaan warna yang mereka miliki menunjukan adanya perbedaan karakter masing-masing. Mereka sama-sama termasuk binatang buas yang ada di hutan. Mereka berinteraksi dengan nafsu dan kepentingannya masing-masing. Bahkan, diantara mereka dengan nafsunya mereka berusaha untuk membunuh yang lain. Sebagaimana nama "rampak" menunjukan dominasi iringan kesenian ini adalah kendang (Nawitri, 2015). Sekilas nampak mirip dengan Jathilan, karena begitu mendalaminya peran yang dilakukan penarinya bisa sampai kesurupan. Dan ada pawang yang biasa mendampinginya.

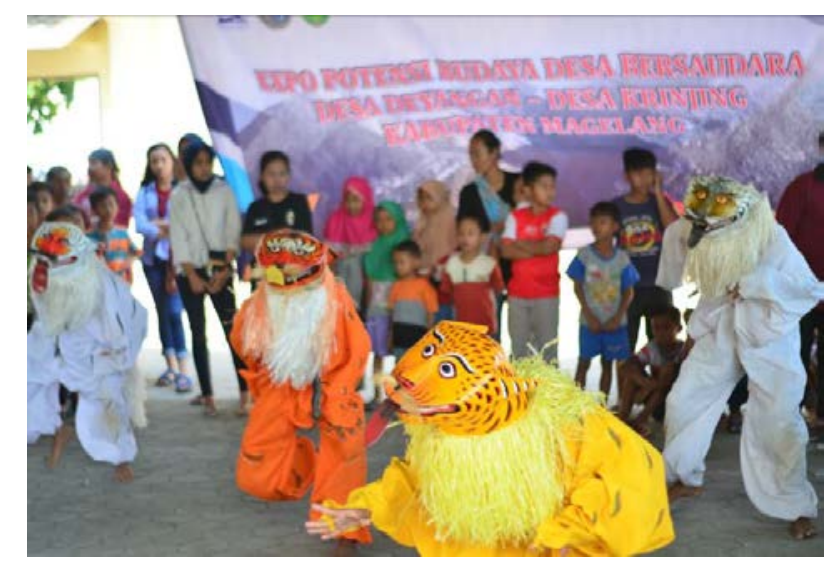

Gambar 7. Rampak Macan 
Temuan dalam kegiatan pengabdian ini adalah peningkatan pengetahuan anggota masyarakat Desa Bersaudara tentang manfaat modal sosial dan kondisi-kondisi yang diharapkan dan selanjutnya dituangkan sebagai dokumen perencanaan program kerja LPBDes dalam implementasi program sister village. Selanjutnya guna mengembangkan modal sosial tersebut dilakukan kegiatan-kegiatan yang mendukung, salah satu diantara adalah Ekspo Potensi Budaya Desa Bersaudara. Kegiatan ini akan diselenggarakan secara rutin. Jika dalam kondisi normal (tidak dalam kondisi tidak ada bencana alam) Ekspo Potensi Budaya Desa Bersaudara akan diselenggarakan dua tahun sekali, dengan penyelenggaraan secara bergiliran. Masyarakat secara luas akan melakukan interaksi dan bekerjasama secara langsung.

\section{KESIMPULAN}

Kegiatan Ekspo Potensi Budaya Desa Bersaudara dalam rangka mitigasi becana diarahkan untuk peningkatan pengembangan pengembangan modal sosial. Karena di dalamnya ada proses perencanaan dan pelaksanaan kegiatan guna peningkatan kualitas silaturahmi diantara keduanya untuk dapat semakin mengenal potensinya masing-masing serta ada mobilisasi massa dari desa yang satu ke desa yang lainnya. Harapannya kegiatan ini memiliki dampak yang positif bagi pada kegiatan mitigasi bencana erupsi Gunung Merapi, karena masyarakatnya sudah saling mengenal dengan baik.

\section{UCAPAN TERIMA KASIH}

Ucapan terima kasih terutama ditujukan kepada Kemenristekdikti yang telah memberikan dana hibah PPDM, Kelompok Mitra LPBDes dan Pemerintah Desa Deyangan, MDMC BPBD Kabupaten Magelang, Kepala Kantor Kecamatan Mertoyudan, Kepala Desa Krinjing, kegiatan atau donatur. Ucapan terima kasih dapat juga disampaikan kepada pihak-pihak yang membantu pelaksanaan kegiatan.

\section{DAFTAR PUSTAKA}

Aswasulasikin. (2017). Partisipasi Masyarakat Desa dalam Pembangunan Pendidikan. Deepublish.

Bhandari, R. B. (2014). Social capital in disaster risk management; a case study of social capital mobilization following the 1934 Kathmandu valley earthquake in Nepal. Disaster Prevention and Management, 23(4), 314-328. https://doi.org/10.1108/DPM-06-2013-0105

BNPB. (2011). Rencana Aksi Rehabilitasi dan Rekonstruksi Pasca Bencana Erupsi Gunung Merapi Kabupaten Magelang 2011-2013.

Coghlan, D., \& Brydon-Miller, M. (2014). Participatory Rural Appraisal. The SAGE Encyclopedia of Action Research, September. https://doi.org/10.4135/9781446294406.n268

Field, J. (2005). Social Capital and Life Long Learning. The Policy Press.

Hapsari, L. (2013). Fungsi Topeng Ireng di Kurahan Kabupaten Magelang. HARMONIA : Jurnal Pengetahuan Dan Pemikiran Seni, 13(2), 141-147. https://doi.org/DOI: 10.15294/harmonia.v13i2.2779

Korten, D. . (1986). Community Management: Asia Experiences and Perspectives. Jumarian Press.

Kusumasari, B. (2014). Managemen Bencana dan Kapabilitas Pemerintah Lokal. Gava Media. 
Mawadda, A. I. (2019). Fenomena Kesenian Gedrug Dalam Kehidupan Masyarakat Desa Limbangan Kecamatan Limbangan Kabupaten Kendal Jawa Tengah. ISI Yogyakarta.

Nawitri, Y. (2015). Nilai-Nilai Pendidikan Karakter Tari Rampak Karya Untung Muljono. Universitas Negeri Yogyakarta.

Pangalila, S. F., Lumenta, A. S. M., \& Nancy J. Tuturoong. (2014). E-Tourisme Kota Tobelo Kabupaten Hamahera Utara. E-Journal Teknik Elektro Dan Komputer Unsrat, 3(1).

Permana, A. (2020). Volkanolog ITB, Mirzam Abdurrachman Jelaskan Tipe Erupsi Gunung Merapi.

Putnam, R. D. (2000). Bowling Alone:The Collapse and Revival of American Community. Simon and Schuster.

Renstra. (2014). Renstra SKPD BPBD Kabupaten Magelang tahun 2014-2019.

RKPD Kabupaten Magelang, (2016).

Sari, K. P., Priyo, P., Oktradiksa, A., \& Setiawan, A. (2018). Sistem Informasi Desa Dalam Mitigasi Bencana (Peran Desa Penyangga Dalam Implementasi Sister Village). Jurnal Pengabdian Kepada Masyarakat MEDITEG, 3(1). https://doi.org/10.34128/mediteg.v3i1.27

Takeuchi.Y, Mulyasari, F., \& Shaw, R. (2011). Disaster Education:Community.Enviroment, and Disaster Management. Emerald Group Publishing Limited.

Tohani, E., \& Wibawa, L. (2019). The role of social capital in disaster management of disaster vulnerable village community on the merapi eruption. Cakrawala Pendidikan, 38(3), 527-539. https://doi.org/10.21831/cp.v38i2.21821

Widodo, A., \& Sujito, S. (2017). Analisis nilai-nilai falsafah Jawa dalam buku pitutur luhur budaya Jawa karya Gunawan Sumodiningrat sebagai sumber belajar pada pembelajaran IPS. Jurnal Penelitian Dan Pendidikan IPS, 11(2), 152-179. 